Proceedings

\title{
Experimental Analysis of CFRP Strengthened Reinforced Concrete Slabs Loaded by Two Independent Explosions ${ }^{\dagger}$
}

\author{
Azer Maazoun 1,2,*, Stijn Matthys ${ }^{1}$, Bachir Belkassem ${ }^{2}$, David Lecompte ${ }^{2}$ and John Vantomme ${ }^{2}$ \\ 1 Magnel Laboratory for Concrete Research, Ghent University, 9052 Gent, Belgium; Stijn.Matthys@UGent.be \\ 2 Civil and Materials Engineering Department, Royal Military Academy, 1000 Brussels, Belgium; \\ bachir.belkassem@hotmail.com (B.B.); David.Lecompte@mil.be (D.L.); Johnny.Vantomme@rma.ac.be (J.V.) \\ * Correspondence: azer.maazoun@ugent.be; Tel.: +32-48-974-1646 \\ + Presented at the 18th International Conference on Experimental Mechanics (ICEM18), Brussels, Belgium, \\ 1-5 July 2018.
}

Published: 11 June 2018

\begin{abstract}
The use of carbon fiber reinforced polymer (CFRP) as an externally bonded reinforcement (EBR) for the strengthening of reinforced concrete (RC) structures loaded by a blast wave is confirmed as an efficient solution. This observation is complementary to other advantages of CFRP such as high tensile strength, light weight and durability. This paper discusses the behavior of CFRP as EBR in the event that two successive independent blast loads are applied on the same target. The main problems are the lack of knowledge regarding the failure modes of the CFRP strips under high strain rate and the blast response of the retrofitted structures when total debonding of the CFRP strips occurs. Four simply supported slabs with different EBR but with the same bond contact surface are tested using an explosive driven shock tube (EDST) to generate the blast wave. Digital image correlation (DIC) is used to measure the strain evolution in the concrete and the CFRP strips during the first explosion. The results show that for the first explosion, EBR increases the flexural strength and stiffness of the RC slabs. In the second explosion, total debonding of the CFRP strips occurs which initiates from the midspan of the slabs towards the supports. When the total debonding of the CFRP strips occurs, the strain distribution in the steel rebars are the same for all slabs regardless of the quantity of applied EBR.
\end{abstract}

Keywords: carbon fiber; blast loading; RC slabs; debonding; two independent explosions

\section{Introduction}

Carbon fiber reinforced polymer (CFRP) is used in diverse strengthening applications such as flexural and shear retrofitting of reinforced concrete (RC) beams, slabs, walls and columns. The previous blast research generally indicated the benefits of using CFRP to enhance the resistance capacity of RC structures [1,2]. However, the blast response of CFRP strengthened RC slabs under two independent explosions has not yet been investigated because of the lack of knowledge regarding the failure modes of the CFRP under high strain rate and the blast response of the retrofitted structures when the debonding of the CFRP strips occurs. This paper presents an experimental analysis of four simply supported RC slabs strengthened with CFRP strips under two independent explosions applied to the same target and where total debonding of the CFRP strips occurs. The primary objectives of this paper are to study the evolution of the strain in the steel reinforcement and CFRP strips during the first explosion and to investigate the effect of the blast wave on the debonding of the CFRP strips due to the propagation of the stresses through the materials during the second explosion. The reflected pressures, maximum deflection and the residual deflection are measured at 
the midspan of the slab as well as the debonding of the CFRP strips after the second detonation are recorded.

\section{Experimental Analysis}

Four RC slabs are examined with the following dimensions: length $2.3 \mathrm{~m}$, width $0.3 \mathrm{~m}$ and thickness $0.06 \mathrm{~m}$. The main reinforcement is composed of 6 bars of $6 \mathrm{~mm}$ diameter. The steel has a design characteristic yield strength of $\mathrm{f}_{\mathrm{y}}=500 \mathrm{~N} / \mathrm{mm}^{2}$, and a Young's modulus of $\mathrm{E}_{\mathrm{s}}=210,000 \mathrm{~N} / \mathrm{mm}^{2}$. The average compressive strength is $\mathrm{fcm}_{\mathrm{cm}}=53 \mathrm{~N} / \mathrm{mm}^{2}$. Only one type of CFRP strip is used for all slabs to be reinforced; it has a length of $1.96 \mathrm{~m}$, a thickness of $2.5 \mathrm{~mm}$ and a width of $15 \mathrm{~mm}$. The tensile strength and Young's modulus of the CFRP (as reported by the manufacture) are $2800 \mathrm{~N} / \mathrm{mm}^{2}$ and $165,000 \mathrm{~N} / \mathrm{mm}^{2}$, respectively. Figure 1 shows the slab internal reinforcement details.

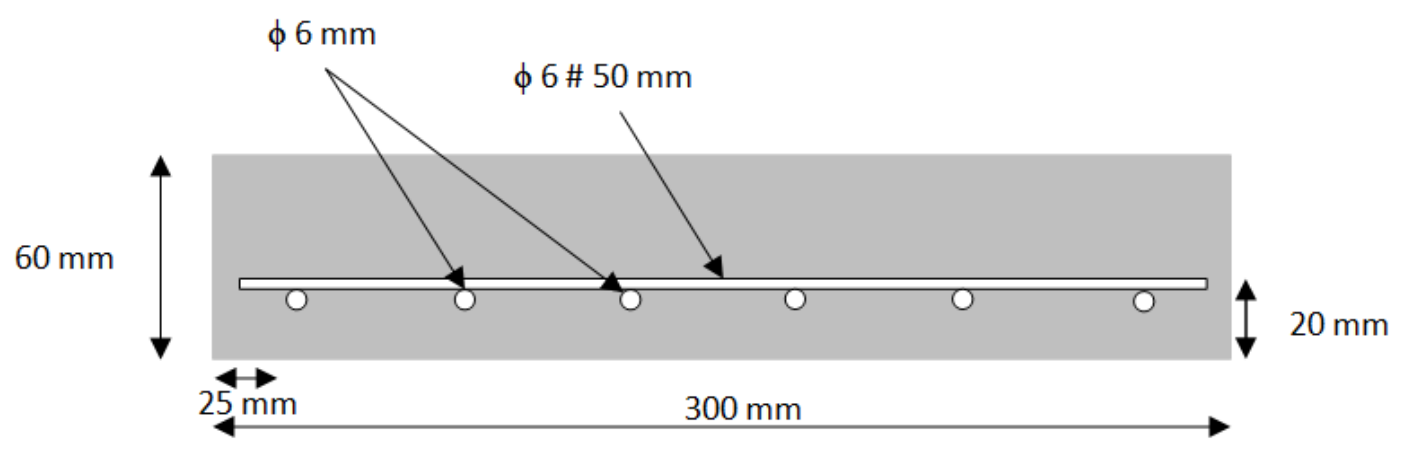

Figure 1. Reinforced concrete (RC) slab details.

Four simply supported slabs with different externally bonded reinforcement (EBR) quantities are tested under two independent explosions but with the same bond contact surface. The slab A1 is used as a control specimen. The slabs A2, A3, and A4 are retrofitted with 1 CFRP strip, 2 CFRP strips and 4 CFRP strips, respectively. Figure 2 shows the tested specimens.

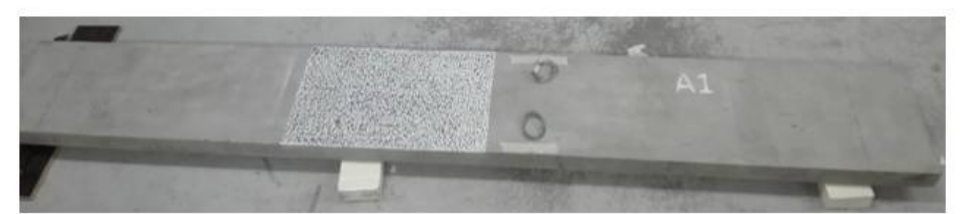

Slab A1: RC slab control specimen

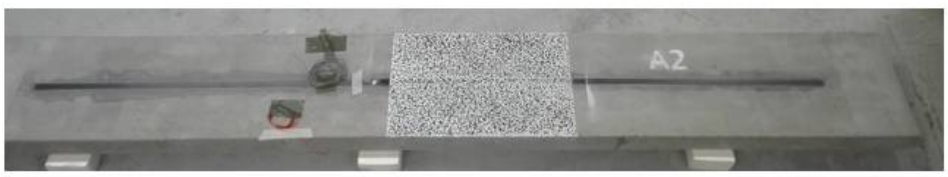

Slab A2: RC slab with FRP strip; $\mathrm{A}_{\mathrm{f}}=37.5 \mathrm{~mm}^{2}$

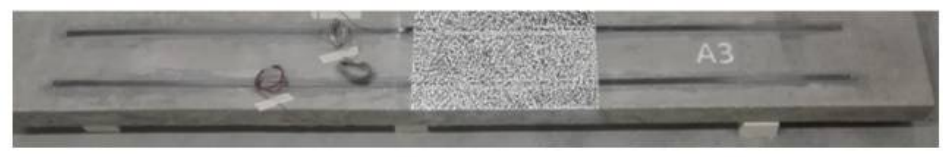

Slab A3: RC slab with FRP strips; $\mathrm{A}_{\mathrm{f}}=75 \mathrm{~mm}^{2}$

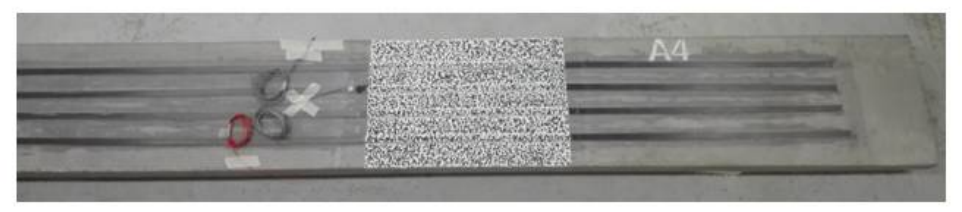

Slab A4: RC slab with FRP strips; $\mathrm{A}_{\mathrm{f}}=150 \mathrm{~mm}^{2}$

Figure 2. Specimens of RC slabs without and with externally bonded reinforcement (EBR). 


\section{Experimental Setup for Blast Tests}

An explosive driven shock tube (EDST) with a square section is used to generate a planar blast wave [3]. For the first explosion, the reflected pressure at the level of the slab is obtained by detonating $40 \mathrm{~g}$ of $\mathrm{C} 4$ at the entrance of the tube as shown in Figure 3.

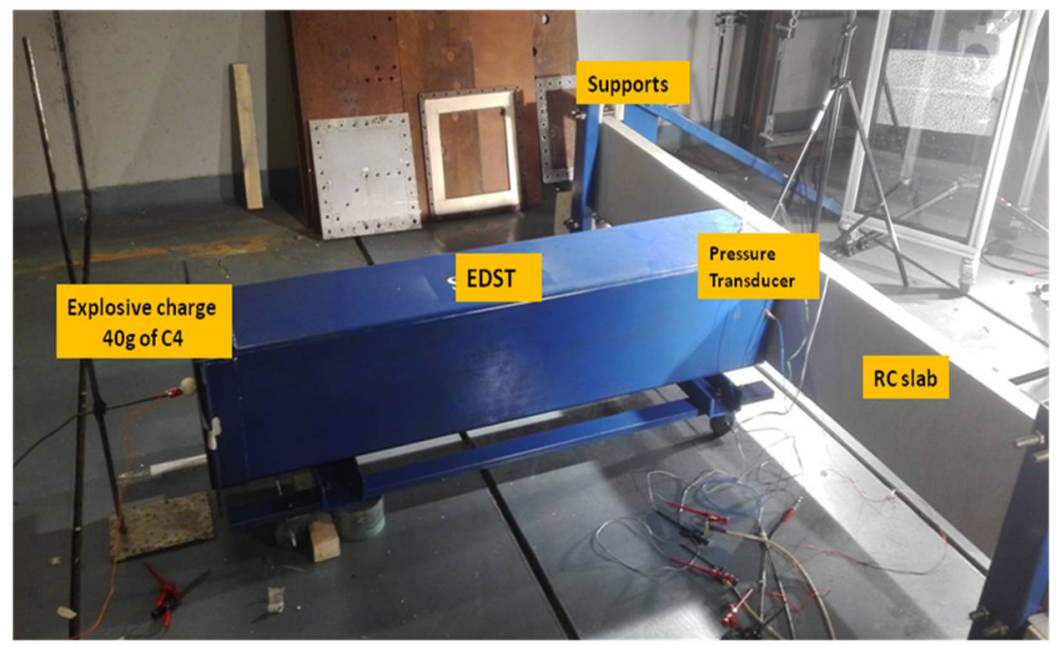

Figure 3. Experimental setup for blast tests.

For the second explosion, the charge weight is increased to $50 \mathrm{~g}$ of $\mathrm{C} 4$ and fixed inside the tube at $30 \mathrm{~cm}$ from the entrance of the tube as shown in Figure 4. This measure is necessary to increase the reflected pressure and the reflected impulse applied to the slab.

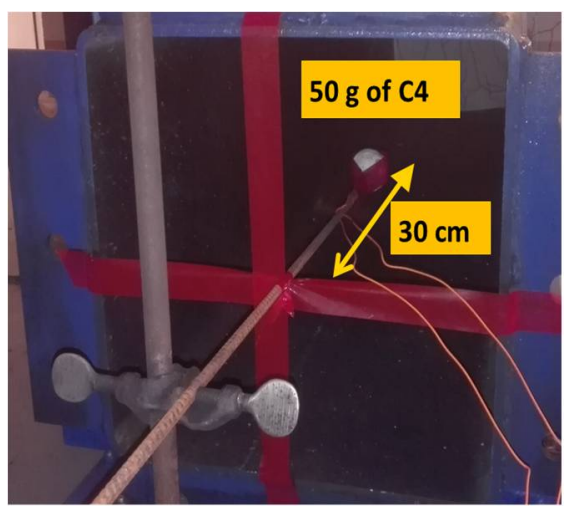

Figure 4. Fixed explosive charge at the entrance of the tube.

\section{Results of the First Explosion}

The maximum deflection at the mid span of the slab and the strain distribution in the steel reinforcement and CFRP strips are recorded as a result of the blast event. The RC slabs reach the maximum deflection during the inbound phase. A summary of the results is shown in Table 1.

Table 1. Experimental results after the first explosion for all four slabs.

\begin{tabular}{cccc}
\hline \multirow{2}{*}{ Specimens } & \multicolumn{3}{c}{ First Explosion $(\mathbf{P r}=\mathbf{3} \mathbf{~ M P a}$, Ir = $\mathbf{1 3 5 0}$ Pa·s) } \\
\cline { 2 - 4 } & $\mathbf{D}_{\max }(\mathbf{m m})$ & $\boldsymbol{\varepsilon}_{\text {s } \max } \mathbf{( \% )}$ & $\boldsymbol{\varepsilon}_{\text {cfrp } \max }(\mathbf{\%})$ \\
\hline A1 & 34 & 0.25 & - \\
A2 & 21 & 0.18 & 0.23 \\
A3 & 20 & 0.17 & 0.21 \\
A4 & 18 & 0.11 & 0.16 \\
\hline
\end{tabular}

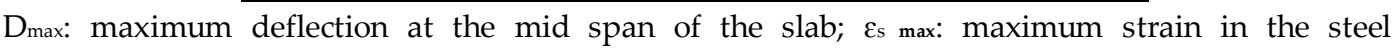

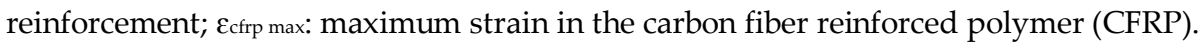


The measurements confirm that EBR significantly increases the blast resistance and the stiffness of the RC slabs and reduces the displacement of the slabs under the blast loading. In all the tests, a reduction in the maximum displacement for all specimens retrofitted with EBR is observed. For example, the retrofitted slab A4 has a deflection of $18 \mathrm{~mm}$ while the control slab A1 has a deflection of $34 \mathrm{~mm}$. The maximum deflection is decreased by $47 \%$. Moreover, increasing the amount of CFRP as EBR leads to a decrease of the strain in the steel rebars. A reduction of $32 \%$ and $56 \%$ of the strain in the steel reinforcement are recorded for the slabs A3 and A4, respectively.

\section{Results of the Second Explosion}

\subsection{Debonding Process}

Using a high-speed camera, images are required to record the debonding process during the second explosion. The recorded images show that the total debonding of the CFRP strips occurs at $5 \mathrm{~ms}$ after the explosion for all the retrofitted RC slabs and the RC slabs reach the maximum deflection after $27 \mathrm{~ms}$. This is shown in Figure 5.

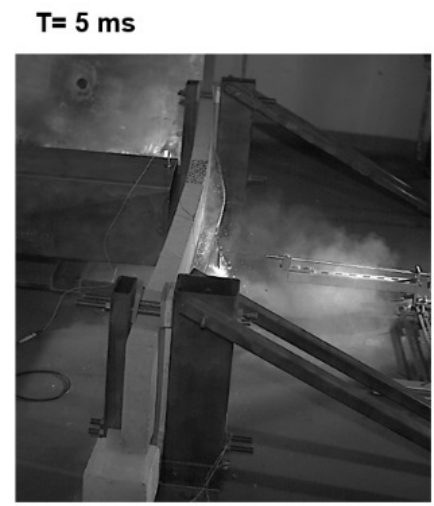

A 2 $\mathbf{T}=\mathbf{2 7} \mathrm{ms}$

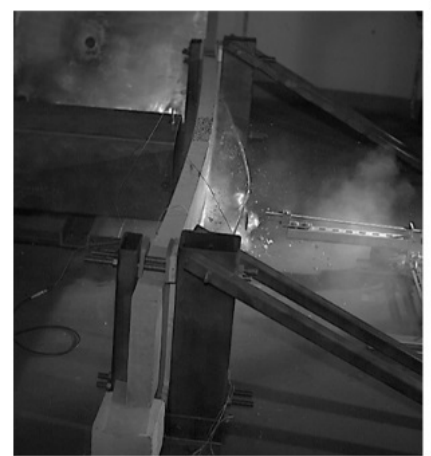

A 2

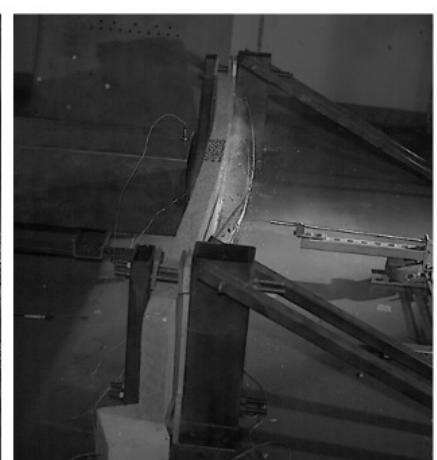

A 3

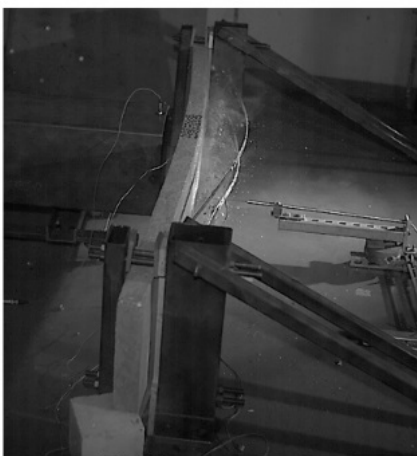

A 3

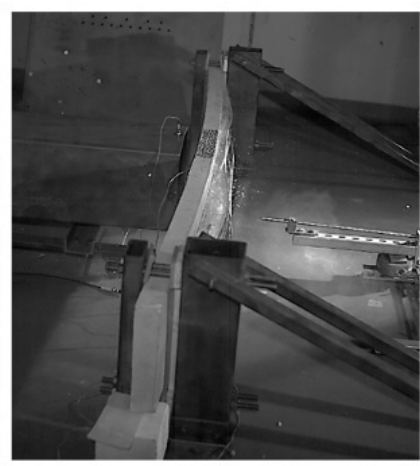

A 4

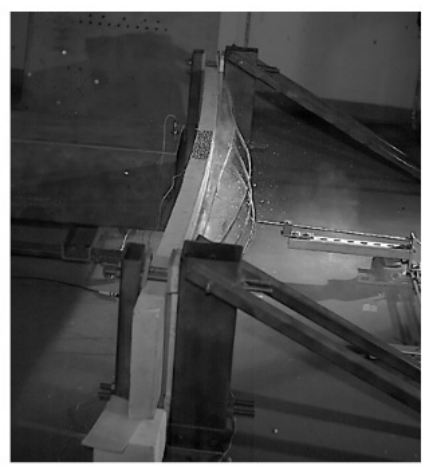

A 4

Figure 5. Debonding of CFRP strips during the second explosion.

During the second explosion, the debonding runs from the midspan of the RC slabs towards the supports in a brittle and sudden manner. This is in accordance with the reported observations that the strengthened elements often fail in a brittle way in the interface between the CFRP and the concrete substrate [4]. The delamination of the CFRP strips occurs with a small concrete layer as shown in Figure 6. 


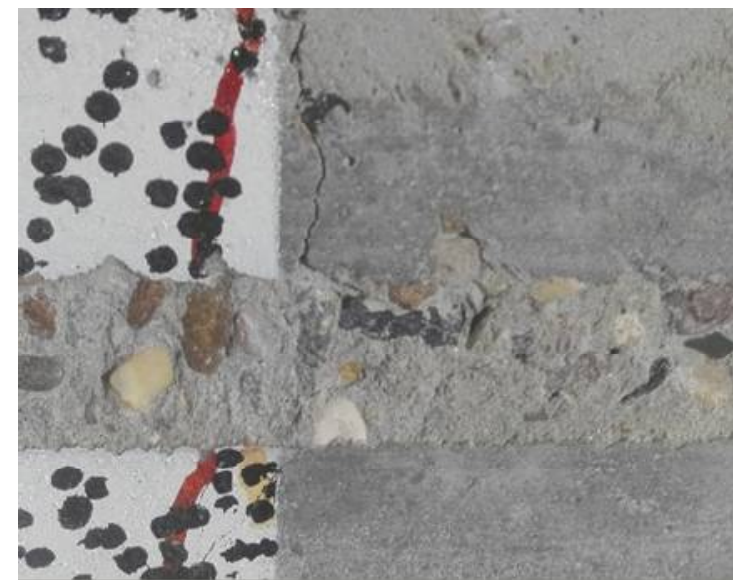

(a)

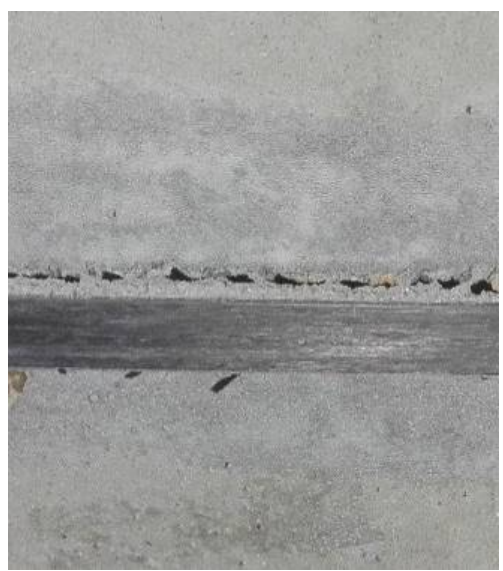

(b)

Figure 6. (a) Delamination zone on the RC slab after the second explosion (b) Debonding at the adhesive-concrete interface with a small concrete layer after the second explosion.

\subsection{Deflection History at Mid Span of the Specimens}

Bonding CFRP strips on the RC slabs provides stiffness to the specimens and changes the blast response of the retrofitted slabs [5]. But when the total debonding of the CFRP strips occurs, all the retrofitted RC slabs experienced the same basic mechanisms, composed by the yielding of the steel and cracking of the concrete as the control specimen. Figure 7 shows the blast response of the RC slabs under a second explosion. The same maximum deflection is recorded for all the slabs during the inbound phase.

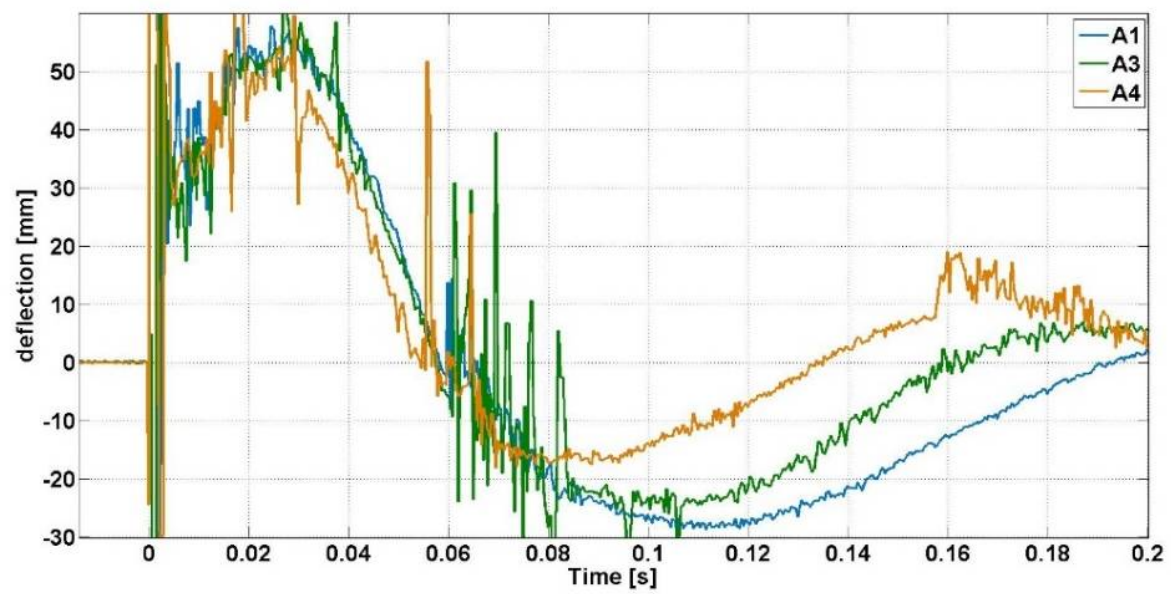

Figure 7. Deflection time history of RC slabs under a second explosion.

\subsection{Strain Evolution in the Steel Reinforcement}

Figure 8 shows the same evolution of the strain in the steel reinforcement during the inbound phase of the second explosion when the total debonding of the CFRP strips occurs. An average of maximum strain equal to $0.16 \%$ is recorded at $t=0.027 \mathrm{~s}$ for all the tested specimens when the $\mathrm{RC}$ slabs reach a maximum deflection. 


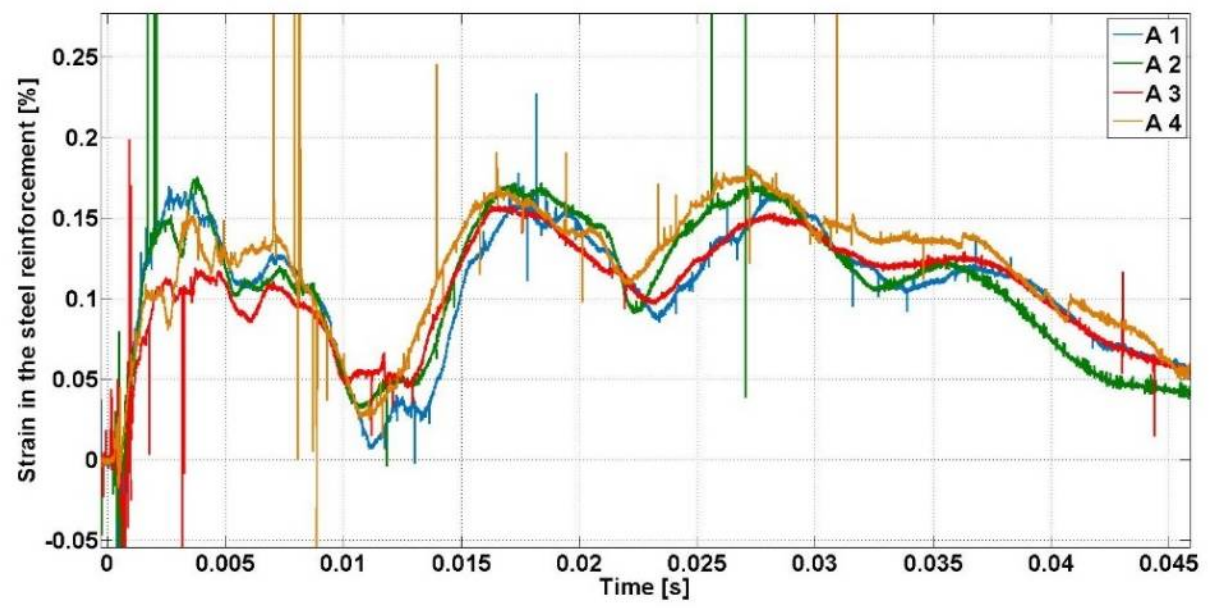

Figure 8. Strain distribution in the steel rebars under the second explosion during the inbound phase.

\section{Conclusions}

This paper presents experimental results of simply supported RC slabs retrofitted with EBR under two successive independent explosions where the total debonding of the CFRP strips occurs in the second explosion. Externally bonded CFRP is efficient to enhance the blast resistance of RC slabs. During the second explosion, total debonding of the CFRP strips runs from the midspan of the RC slabs towards the supports in a brittle and sudden manner, and when the total debonding occurs the retrofitted slabs behave as the control specimen without EBR (yielding of the steel and cracking of the concrete).

Acknowledgments: The authors thank the company Sika for providing the CFRP strips.

\section{References}

1. Maazoun, A.; Matthys, S.; Vantomme, J. Literature review on blast protection by externally bonded FRP reinforcement. In Proceedings COST TU1207 End-of-Action Conference, Budapest, Hungary, 3-5 April 2017; pp. 1-6.

2. Minor, J.K.; Coleman, T.G. Experimental Testing of CFRP-Strengthened Reinforced Concrete Slab Elements Loaded by Close-In Blast. J. Struct. Eng. 2014, 140, 04013060.

3. Ousji, H.; Belkassem, B.; Louar, M.A.; Kakogiannis, D.; Reymen, B.; Pyl, L.; Vantomme, J. Parametric Study of an Explosive-Driven Shock Tube as Blast. Exp. Tech. 2015, doi:10.1111/ext.12179.

4. Fédération Internationale du Béton (Fib). Externally Applied FRP Reinforcement for Concrete Structures; Fib Bulletin; International Federation for Structural Concrete: Lausanne, Switzerland, 2001.

5. Maazoun, A.; Belkassem, B.; Reymen, B.; Matthys, S.; Vantomme, J.; Lecompte, D. Blast response of RC slabs with externally bonded reinforcement: Experimental and analytical verification. Compos. Struct. 2018, $200,246-257$.

(C) 2018 by the authors. Licensee MDPI, Basel, Switzerland. This article is an open access article distributed under the terms and conditions of the Creative Commons Attribution (CC BY) license (http://creativecommons.org/licenses/by/4.0/). 